УДК 94.687 (470.42)

ТЕКСТИЛЬНАЯ ОТРАСЛЬ ПРОМЫШЛЕННОСТИ УЛЬЯНОВСКОЙ ОБЛАСТИ В 1941-1945 ГТ.

\author{
(c) 2020 М.В. Чигрин
}

Ульяновский государственный педагогический университет им. И.Н. Ульянова

Статья поступила в редакцию 17.06.2020

\begin{abstract}
В статье на базе привлеченных ранее неизвестных архивных документов охарактеризован процесс развития текстильной отрасли легкой промышленности Ульяновской области в 1941-1945 гг. Автор рассматривает показатели деятельности предприятий текстильной промышленности, ход социалистических соревнований, а также анализирует факторы, которые препятствовали освоению производственных мощностей.

Ключевые слова: Великая Отечественная война, Ульяновская область, производственная деятельность, швейные фабрики, продукция, сырье.
\end{abstract}

DOI: 10.37313/2658-4816-2020-2-2-32-40

Великая Отечественная война, начавшаяся 22 июня 1941 года, повлекла за собой серию срочных масштабных мероприятий, охватывающих все сектора экономики, которые стихийно перестраивались на военный лад - интенсивно наращивались темпы производства, а также организовывались учреждения по подготовке кадров для отраслей промышленности. Легкая промышленность Ульяновского края в военный период занимала второе место по удельному весу и работала непосредственно для обеспечения нужд Красной Армии ${ }^{1}$ Производственные показатели легкой промышленности росли, но плановые показатели периодически не выполнялись. Например, в 1941 году швейные фабрики недодали армии 350 тысяч шинелей ${ }^{2}$. Во многом это было вызвано тем, что не имелось в достаточном количестве ресурсов, в особенности электроэнергии, топлива и транспорта, без которых простаивала текстильная промышленность. В частности, на Мулловской суконной фабрике не было ни одной исправной машины, из-за чего фабрика не заготовила топливо и не смогла выполнить план по производству шинельного сукна ${ }^{3}$.

Чигрин Максим Валерьевич, аспирант.

E-mail:maksim-chigrin@mail.ru
В то же время в 1941 году на швейной фабрике № 5 был досрочно выполнен ежегодный план в рамках социалистического соревнования с Куйбышевской швейной фабрикой № 24 . Непосредственно были достигнуты следующие показатели: снижена себестоимость продукции на 7\%, внедрено 44 рационализаторских предложения, а также запущено 6 параллельных агрегатов ${ }^{5}$. Во многом удалось достигнуть таких показателей благодаря организации контроля за ходом производственной деятельности со стороны руководства. Огромных результатов достигли Фомина Мария, выполнившая годовой план на 146\%, Александрова Анастасия - на $160 \%$, швея Парамонова - на $147 \%^{6}$.

Стоит отметить, до начала проведения социалистического соревнования производственные показатели были значительно хуже. Например, до заключения договора группа Парамоновой выполняла план лишь на 106\%. На фабрике было организовано также и соревнование между бригадами, в котором приняло участие 15 коллективов ${ }^{7}$. Закройный цех № 1, возглавляемый Воронковым, соревновался с пошивочным цехом № $3^{8}$. По результатам ежегодного соревнования победил закройный цех, который систематически строго соблюдал график работ, не допускал брак, довел производи- 
тельность труда в среднем до 130-160\%, а также сэкономил сырья на общую сумму в 450 тысяч рублей9.

Швейный завод № 8, организованный на базе швейкомбината им. Ворошилова, также успешно выполнял государственные заказы. По итогам производственных показателей 1941 года на предприятии получили благодарность свыше 15 стахановцев, двухсотников и трехсотников ${ }^{10}$. Коллектив швейкомбината включился в ноябре 1941 года и во фронтовой декадник, чтобы оказать помощь защитникам Сталинграда. Так, секретарь парторганизации комбината А. Лукьянова заявляла о решении коллектива: «Сталинград вдохновляет наш народ на новые трудовые подвиги. В связи с этим, мы рабочие и служащие должны жить одним чувством, одним стремлением - помочь Сталинграду в эту нелегкую минуту...» ${ }^{11}$. Значительно усложняло выполнение поставленной задачи систематическое отсутствие электроэнергии, из-за чего работницы были вынуждены изготовлять изделия, пользуясь ножными машинами. На предприятии было развернуто индивидуальное социалистическое состязание, а также грамотно поставлен учет производственной деятельности - была организована доска показателей, книга прогулов и дневник нормы. За фронтовую декаду комбинатом план был выполнен на 154\%, а себестоимость продукции снижена к показателям предыдущего квартала на $6 \%{ }^{12}$. Кроме этого, работники комбината по собственной инициативе приняли решение отправить за ноябрь и декабрь четырехдневный заработок на приобретение теплых вещей для фронтовиков.

В 1942-1943 годах высокие производственные показатели были и у Барышской грубосуконной фабрики им. Свердлова, которая ежегодно выполняла в среднем план на 132\% ${ }^{13}$. За достигнутые успехи в июле 1943 года решением бюро обкома партии коллективу предприятия было присуждено переходящее Красное Знамя. Хороших показателей за обозначенный период достиг и коллектив фабрики 3 Интернационала - 104\% ${ }^{14}$.
Фабрика им. Ленина в 1941-1943 годы систематически не выполняла плановых показателей. Предприятие имело 14 автомашин и 90 лошадей, однако не сумело организовать доставку сырьевых ресурсов, из-за чего имело значительные временные простои ${ }^{15}$. Нарушение производственного ритма объяснялось и большими простоями оборудования. Так, если по плану предприятия был предусмотрен простой станков не более чем $4 \%$ от общего количества рабочего времени, то на фабрике данный показатель превышал $20 \%{ }^{16}$. По сельфакторам фактические простои шестикратно превышали установленную в документации цифру, а по ткацким станкам - четырехкратно. Во многом оборудование простаивало изза дефицита запасных частей, которые не имела возможности изготавливать литейная мастерская, не функционировавшая по причине отсутствия угля. На предприятии к организации соцсоревнования руководство относилось формально, зачастую заключая договоры по трафарету. Наряду с этим встречались и случаи, когда рабочий брал на себя индивидуальное обязательство выполнять плановые показатели в более низком объеме, нежели он выполнял в данный момент. Разъяснительные беседы с таким работником не проводились, что подрывало уровень дисциплины. Так, в 1943 году на предприятии было зафиксировано более 50 грубых нарушений законов о труде, только 67 сдельщиков (35,7\%) справились с индивидуальными занятиями, а в ночных сменах производительность труда была в среднем на $20 \%$ ниже, нежели в дневных ${ }^{17}$. Халатно относилось руководство на предприятии к подбору командных кадров. В частности, лишь за 1943 год в аппаратно-прядильном цехе сменилось 4 начальника ${ }^{18}$.

В 1943 году барышские суконные фабрики, фабрика им. Гладышева столкнулись с острым дефицитом топлива, который был вызван невозможностью своевременной доставки торфа. Так, за год фабриками было получено лишь 15 тысяч тонн торфа, в то время как требовалось для эффективной и 
бесперебойной работы суммарно 120 тысяч тонн $^{19}$. Мулловская фабрика в 1943 году простояла 70 дней по причине изношенности трубы. Директор фабрики Стригальщиков не заботился и о пополнении предприятия квалифицированными кадрами, что не позволяло в полной мере организовать производственную деятельность ${ }^{20}$. Результатом такого отношения стал низкий показатель выполнения плана за 1943 год - 56\% ${ }^{21}$. Отставала фабрика им. Калинина вследствие возникших трудностей с транспортировкой сырьевых ресурсов. Так, за 1943 год предприятие простояло без работы более 4 месяцев ${ }^{22}$.

В 1944 году коллективу фабрики им. КИМ удалось выполнить план на 101,6\%, фабрике им. Степана Разина - на $42 \%$, им. Калинина на 50\%, им. Тинякова - на 38\%, им. Горького - на 53\%, комбината «Ударник» - на $41 \%{ }^{23}$. Во многом такие показатели были обусловлены прежде всего тем, что хозяйственные и партийные руководители предприятий не сумели грамотно организовать контроль за ходом производственной деятельности рабочих.
В связи с низким качеством партийнополитической, массовой работы, отсутствием организации приемлемых бытовых условий для рабочих резко возросла кадровая текучесть. Так, за 1944 год из предприятий текстильной промышленности убыло по разного рода причинам 1218 человек, причем 1073 из них покинули работу самовольно $^{24}$. В 1945 году из предприятий текстильной промышленности убыло 1567 человек ${ }^{25}$. Также на предприятиях текстильной отрасли Ульяновской области отмечалось и массовое снижение уровня дисциплины (см. диаграмму 1).

Исходя из диаграммы видно, что на предприятиях текстильной отрасли легкой промышленности Ульяновской области в период Великой Отечественной войны всего было зафиксировано 26362 случая нарушения дисциплины. Среди них приходилось: на самовольный уход $33,7 \%$, на прогулы - 27,5\%, на прочие нарушения - $23,5 \%$ и на опоздания $-15,3 \%$. Во многом столь большое количество со-

Диаграмма 1. Состояние трудовой дисциплины на предприятиях текстильной отрасли легкой промышленности Ульяновской области в 1941-1945 гг.

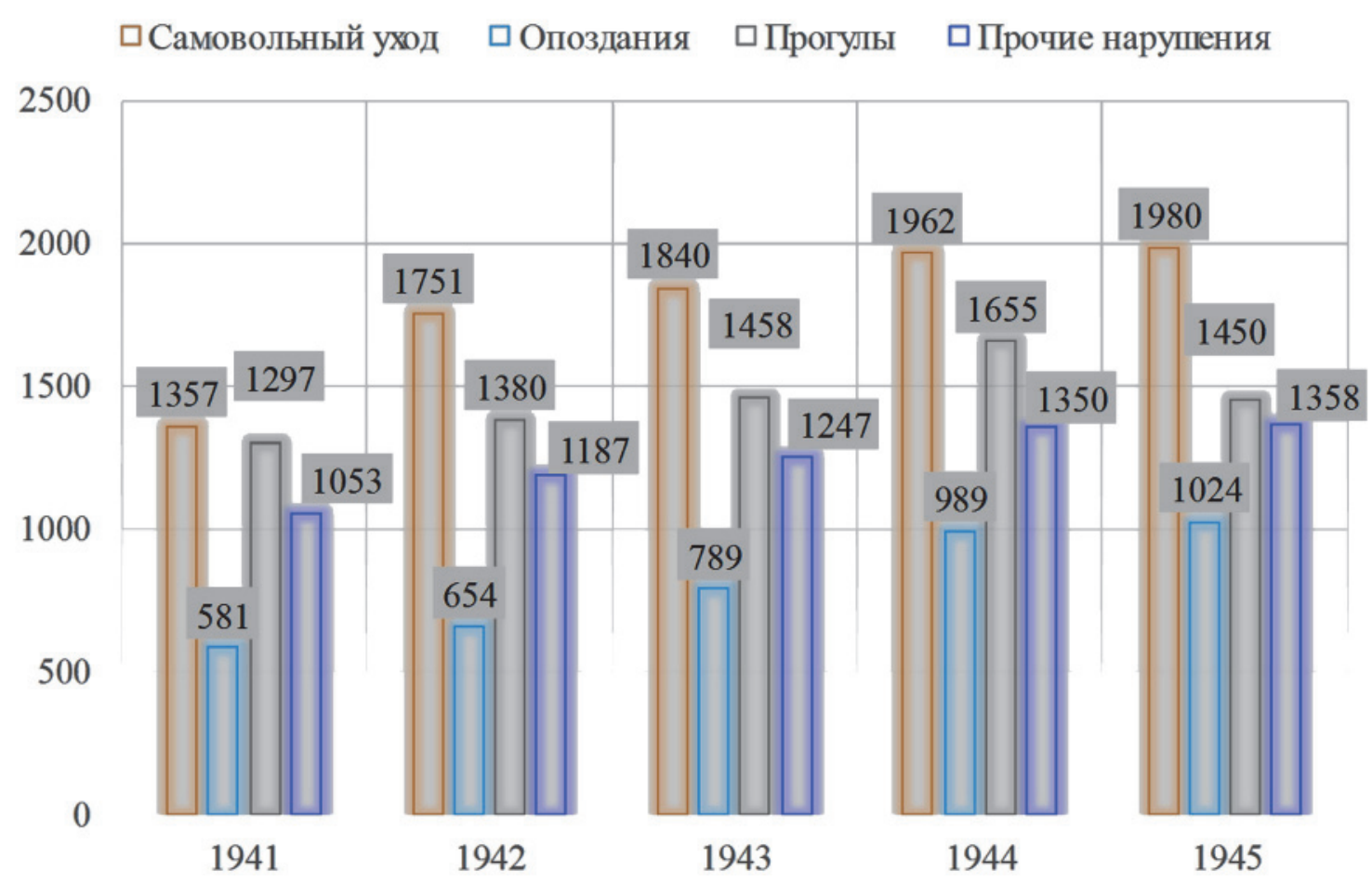

*Составлено по материалам: ГАНИ УО. Ф. 8. ОП. 2. Д. 318. Л. 4-15; ОП. 3. Д. 320. Л. 10-15; ГАУО. Ф. Р-99. Оп. 2. Д. 11. Л. 4-9. 
вершенных дисциплинарных нарушений можно объяснить значительно возросшей физической и психологической нагрузкой на рабочих, а также неуверенностью в завтрашнем дне.

На предприятиях области укрепление дисциплинарного уровня проводилось посредством администрирования и практики массового наложения взысканий на провинившихся рабочих. Всего по области взысканию подверглись свыше 2000 рабочих. В частности, на фабрике им. Интернационала за 1943-1945 годы было передано под суд 467 человек, наложено 327 взысканий на рабочих ${ }^{26}$. Поощрено же за высокий производительный уровень на предприятии было 87 человек. Взысканию подвергся и директор фабрики Пятибратов. Аналогичным образом ситуация складывалась и на фабрике им. Калинина, где за двухлетний период было зафиксировано 864 случая нарушения трудовой дисциплины, среди которых наибольшее распространение получил самовольный побег - 632 случая ${ }^{27}$.

В большей части предприятий состояние материально-технической базы оставалось на протяжении всего военного периода на низком уровне. Так, на швейной фабрике № 5 из 8 агрегатов исправно функционировали только 5, на фабрике им. Горького из 6 3 , на фабрике им. Типякова из $10-7^{28}$. Свободное оборудование фабрик зачастую не ремонтировалось, а при достижении крайней изношенности оборудования руководством не принимались меры для создания в областном центре собственной ремонтной базы, где бы наряду с капитальным ремонтом машин и другого оборудования производилось бы изготовление запасных частей. Кроме этого, швейные фабрики испытывали и нужду в транспорте ${ }^{29}$. В частности, некоторые фабрики были вынуждены сырье, топливо и готовую продукцию транспортировать на машинах, принадлежащих другим организациям. Во многом это было связано с тем, что за годы войны гужевой транспорт фабрик не только не пополнился, но и значительно сократился, а расчет на создание собственного автопарка при предприятиях не оправдался ${ }^{30}$.

В 1944 году ряд фабрик Ульяновской области смог успешно выполнить годовой план. Например, фабрика им. Гладышева добилась перевыполнения плановых показателей на $20 \%{ }^{31}$. Бригада Ежовой добилась выполнения производственного плана на $117,3 \%$, а также сэкономили сырья на сумму 1800 рублей. Коммунистическая бригада А. Медведевой сумела организовать работу таким образом, что выполняла сложные задания в среднем за восемь часов при увеличенной продолжительности рабочего дня ${ }^{32}$. По результатам соревнования были отмечены благодарственными грамотами рабочие аппаратно-прядильного цеха: секретчицы - К. Кирюшина, А. Ларина, Сорокина, Скердонова и прядильщица Д. Лопухова ${ }^{33}$.

Особое внимание руководство уделяло и решению кадровой проблемы. Так, на предприятии было организовано ускоренное обучение молодых рабочих по профессиям секретчиков и винтовщиков. К наставничеству привлекались стахановцы и передовики производства. Например, К. Кирюшина, задействованная на фабрике в 1943 году на суконном производстве, прошла обучение под руководством инструктора Е. Моисеевой и освоила профессию секретчицы ${ }^{34}$. Уже начиная с 1944 года Кирюшина не только добилась высоких производственных показателей, но и стала выполнять роль наставницы для молодых работниц, за что получила правительственную награду «За трудовое отличие». Также директор фабрики Гумбург был награжден орденом «Знак Почета», а ткачиха Невлютова - медалью «За трудовое отличие» ${ }^{35}$.

На фабрике прошли обучение по профессии секретчицы: А. Грибова, Л. Сорокина, Никитина, Трофимова, Панкратова, Лизунова. Одновременно с учебой рабочих на предприятии осуществлялась и подготовка помощников мастеров из числа женщинстахановок. Получили азы профессии поммастера: Данилина, Ваницкова, Кирьянова, Зубкова и Щербакова. Две помощницы 
П. Ховрина и Ю. Кошелева после прохождения краткосрочного обучения на предприятии были командированы на курсы мастеров с отрывом от производственной деятельности ${ }^{36}$. Представляется целесообразным для получения более достоверной картины организации производства на предприятии привести интервью ткачихи А. Мосейкиной «Ульяновской правде»: «Трудовой день я начинаю на 20-30 минут раньше гудка, чтобы успеть смазать машину, привести в порядок рабочую форму, а также расправить все нити на станке. В военное время, после перехода на трехстаночное обслуживание, мне приходилось выкраивать фактически каждую минуту. Крайне важно было не потерять время, а для этого приходилось изучать техническую документацию на станок. Старалась есть быстрее, ведь ежеминутно помнила, что Красная Армия идет вперед, из-за чего я должна халтурить...» ${ }^{37}$.

Большую роль в повышении качества производственной деятельности сыграли изобретатели и рационализаторы. Например, В. Саранцев переоборудовал станок для изготовления веревок, а главный механик С.И. Петров усовершенствовал принцип ремонта изношенных деталей ${ }^{38}$. Благодаря деятельности рационализаторов механика Виленского и начальника мойки Тезикова были механизированы горячая и холодная промывки за счет использования электроэнергии дизеля, находящегося от мойки на расстоянии 0,6 километра. Внесение данного рационализаторского предложения позволило предприятию сэкономить 700 тысяч рублей ${ }^{39}$.

Положительная производственная динамика на предприятиях текстильной отрасли легкой промышленности сохранилась и в 1945 году. Так, за первые два квартала 1945 года коллектив фабрики КИМ по итогам социалистического соревнования сумел дать сверхплановой продукции на 40 тысяч рублей, досрочно выполнить план и сдать в фонд Верховного Главнокомандования 8 тысяч пар чулочных изделий и 400 свитеров, пустить в эксплуатацию 8 автоматов 17 класса и 4 машины 22 класса ${ }^{40}$. Успеху соревнования способствовали систематическая проверка выполнения договоров, лицевые счета, Доски почета, лозунги, плакаты, бюллетени и стенгазеты, освещающие ход соревнования ${ }^{41}$.

Соревнованием были охвачены все производственные участки. Высоких показателей достигла бригада смены «Б» Шарагиной, выработавшая сверх плана 850 пар носков. На кетельных участках приняли участие в соревновании две комсомольские бригады, по итогу которого смогли закетлевать сверх плана 1250 пар чулок и носков. При этом стахановки Евсеева, Железнякова, Константинова и М. Коган стали двухсотниками и трехсотниками. Помогали усовершенствовать производство и рационализаторы. Так, инженер Баранов предложил способ изготовления звеньев счетной цепи к чулочным автоматам, что дало 15100 рублей экономии ${ }^{42}$. Звенья по его методу были установлены на 5 автоматах. Мастер Новиков внес предложение применять на мотальных машинах парафинеры упрощенной конструкции, что позволило улучшить качество переработки сырья. Начальник закройного цеха Пуринсон предложил изменить способ обрезки сверловочной цепочки в начале шва, что уменьшило расход пряжи при пошиве трикотажных изделий ${ }^{43}$. По инициативе партии в мае была произведена проверка качества работы на предприятии. В ходе проверки квалифицированные работницы были освобождены от подсобных работ (отделки рисунчатых носков на сверловке, обрезки цепочки на сортировке), проведена фотосъемка рабочего дня передовых производственниц с целью последующей передачи данных снимков отстающим ${ }^{44}$.

В цехах фабрики им. Гладышева плановые показатели за первую половину 1945 года были выполнены на 105\% ${ }^{45}$. Директор Гумбург и главный инженер Варшавер сумели создать рабочим все необходимые условия для производительного труда. Непосредственно была организована тех- 
ническая помощь кадровиков молодым рабочим, улучшилось бытовое обслуживание коллектива: медицинская помощь, качество общественного питания ${ }^{46}$. Также было создано рабочее общежитие и отремонтированы десятки квартир сотрудников. На фабрике была широко развернута и массово-политическая работа - с отстающими проводились коллективные и индивидуальные беседы, в цехах вывешивались «Молнии» и «Боевые листки», результаты каждого месяца обсуждались на цеховых и бригадных производственных совещаниях. Согласно докладу начальника аппаратнопрядильного цеха Селезнева от 7 мая 1945 года: «... раньше наш цех заметно отставал от остальных, добрая половина секретчиц и прядильщиков плановых норм не выполняла. Сейчас, когда коллектив включился в соревнование, положение резко изменилось» ${ }^{47}$. По итогу соревнования секретчица - орденоносец Карюшина довела выполнение сменных норм до 150\%, секретчицы М. Сокшева и Л. Сорокина, ранее не вырабатывавшие норм, выполнили план соответственно на 115 и $120 \%{ }^{48}$.

Коллектив фабрики им. Клары Цеткин за аналогичный период добился выполнения показателей на $114,5 \%{ }^{49}$. На фабрике обучение молодых сотрудников проходило под чутким контролем со стороны более опытных работников, что позволяло быстро повышать квалификационный уровень. Так, молодая работница Е. Терехина уже спустя полгода стала одной из лучших наладчиц чулочного цеха и приступила к подготовке кадров, обучая новичков работе на чулочных автоматах. На передовом собрании ей была вручена премия за производственные успехи. Наряду с Терехиной высоких результатов достигли и Николаева, выработавшая 146\% задания, и вязальщица Загорская, выполнившая план на $138 \%{ }^{50}$. Выдающихся результатов достигли и работники швейного цеха. Так. бригадир Волчек и Ященюк сдали 4500 бельевых изделий вместо 2600, а работницы Слюняева, Хохлова и Андрюшина вдвое перевыполнили установленные нормы $^{51}$.

В целом в Ульяновской области швейным фабрикам за период Великой Отечественной войны не удалось выполнить в полной мере значительно возросшие плановые показатели. Так, из запланированных 8,5 миллиона шинелей было выпущено только 4,3 миллиона штук, из-за чего бойцы армии

Диаграмма 2. Показатели валовой продукции текстильной отрасли промышленности (включая трикотажную и валяльно-войлочную) Ульяновской области в 1941-1945 гг.

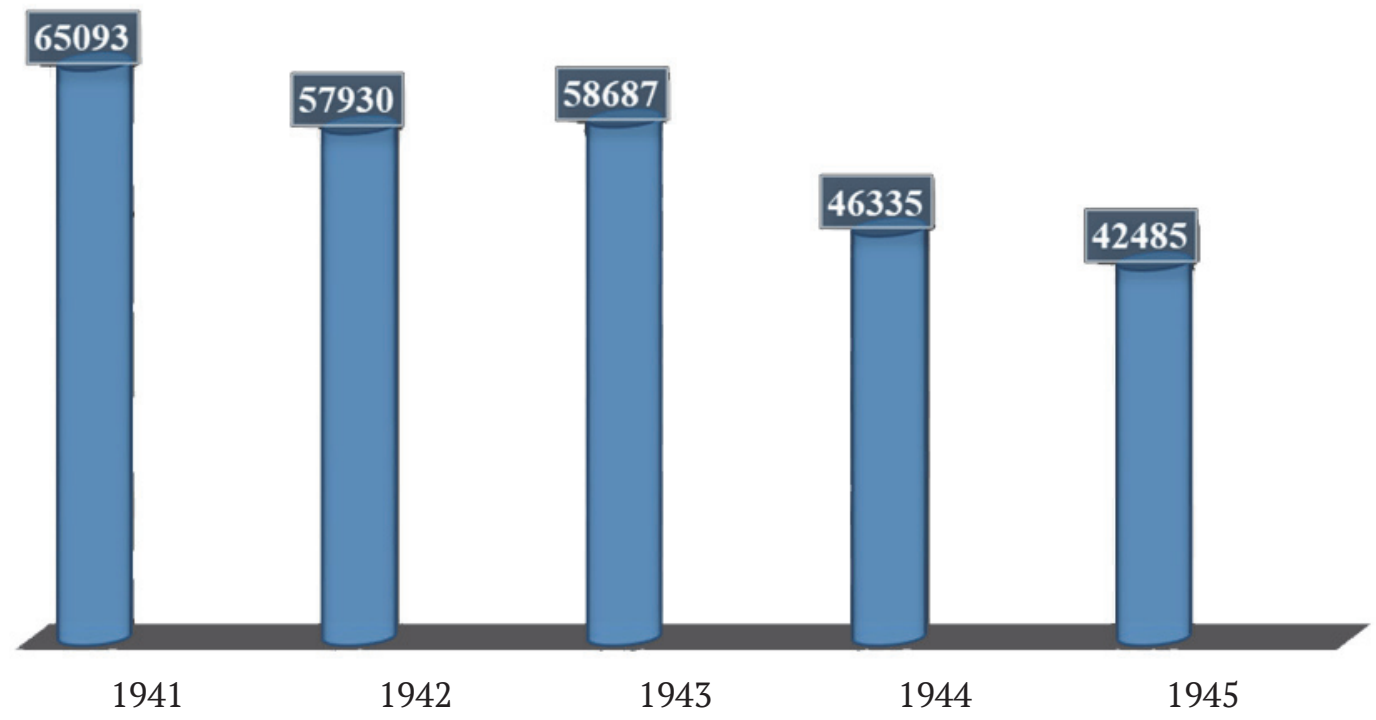

*Составлено по материалам: Пашкин А.Г., Забалухина Н.В. Симбирский - Ульяновский край в новейшей истории России. 1917-1991. Люди, события, факты. Ульяновск: Корпорация технологий продвижения, 2012. С. 181. 
недополучили 4,2 миллиона шинелей ${ }^{52}$. Основные показатели текстильной отрасли промышленности, включая трикотажную, шерстяную и валяльно-войлочную, за период Великой Отечественной войны представлены на диаграмме (см. диаграмму 2).

Согласно данным вышепредставленной диаграммы в Ульяновской области отмечался постепенный спад уровня производства, который во многом был вызван началом Великой Отечественной войны. Так, в 1945 году показатель валовой продукции по сравнению с 1941 годом упал на $53,2 \%$. Для получения более полной ретроспективной картины, нам представляется целесообразным проследить реализацию предприятиями текстильной промышлен- ности плановых показателей и по выпуску валовой продукции конкретных предприятий по ниже представленной таблице (см. табл. 1).

Анализируя данные таблицы, можно утверждать, что в Ульяновской области успешно справлялись с выполнением плановых показателей за период Великой Отечественной войны лишь 4 предприятия: суконная фабрика им. Гладышева, трикотажные фабрики им. КИМ и Клары Цеткин, а также ателье Главтрикотаж. На текстильных предприятиях основным фактором, который препятствовал реализации в полной мере производственного плана, являлось наличие простоев оборудования, а также неудовлетворительное проведение капи-

Таблица 1. Выполнение плана по выпуску валовой продукции суконными и швейными предприятиями текстильной промышленности Ульяновской области за 1941-1945 гг. (в руб.).

\begin{tabular}{|l|l|l|l|l|}
\hline № & Наименование предприятия & План & $\begin{array}{l}\text { Фактически } \\
\text { выполнено }\end{array}$ & $\begin{array}{l}\text { \% } \\
\text { выполнения } \\
\text { плана }\end{array}$ \\
\hline 1 & Суконная фабрика им. Ленина & 28558 & 18141 & 63,5 \\
\hline 2 & $\begin{array}{l}\text { Суконная фабрика им. } \\
\text { Гладышева }\end{array}$ & 35444,5 & 35516 & 100,2 \\
\hline 3 & $\begin{array}{l}\text { Суконная фабрика им. } \\
\text { Свердлова }\end{array}$ & 22588 & 16628 & 73,6 \\
\hline 4 & $\begin{array}{l}\text { Суконная фабрика 3 } \\
\text { Интернационала }\end{array}$ & 22562 & 15363 & 68 \\
\hline 5 & $\begin{array}{l}\text { Суконная фабрика им. } \\
\text { Степана Разина }\end{array}$ & 29913 & 12770 & 42,7 \\
\hline 6 & $\begin{array}{l}\text { Суконная фабрика им. } \\
\text { Калинина }\end{array}$ & 37527,5 & 18862 & 50,3 \\
\hline 7 & Суконная фабрика им. Гимова & 27218 & 23558 & 86,6 \\
\hline 8 & Мулловская фабрика & 32903 & 19233 & 58,5 \\
\hline 9 & Фабрика № 5 & 102603 & 58587,5 & 57,1 \\
\hline 10 & Фабрика им. Горького & 68828 & 36693,5 & 53,3 \\
\hline 11 & Фабрика им. Тинякова & 101790 & 38608 & 37,9 \\
\hline 12 & Фабрика № 4 & 101785 & 59976 & 58,9 \\
\hline 13 & $\begin{array}{l}\text { Трикотажная фабрика им. } \\
\text { КИм }\end{array}$ & 17100 & 17359 & 101,5 \\
\hline 14 & $\begin{array}{l}\text { Трикотажная фабрика им. } \\
\text { Клары Цеткин }\end{array}$ & 16830 & 17319,5 & 102,9 \\
\hline 15 & Ателье Главтрикотаж & 4600 & 4615,5 & 120,3 \\
\hline
\end{tabular}

*Составлено по материалам: ГАНИ УО. Ф. 8. ОП. 3. Д 318. Л. 4-12; Д. 320. Л. 25-29; ГАУО. Ф. Р-3137. ОП. 1. Д. 48. Л. 16. 
тального и планово-предупредительного ремонта оборудования.

Таким образом, в годы Великой Отечественной войны Ульяновский край, как и все советское государство, столкнулся с целым рядом тяжелейших испытаний, а непрекращающиеся военные действия систематически требовали от промышленных предприятий аккумулирования всех внутренних экономических резервов. Текстильная отрасль легкой промышленности наряду с военно-промышленным комплексом играла одну из ключевых ролей и выполняла важнейшую задачу - поставляла продукцию для нужд Красной армии и гражданского населения. Однако стоит учитывать, что установленные государством завышенные плановые показатели для большинства предприятий текстильной отрасли легкой промышленности оказались непосильны, прежде всего из-за острого дефицита сырьевой базы и кадровых специалистов, а также отсутствия бесперебойного функционирования транспортного сообщения.

\section{ПРИМЕЧАНИЯ}

${ }^{1}$ Мухамедов Р.А., Архипов Д.В. Территориальное устройство Ульяновской области в 1943 г. // Вестник НИИ гуманитарных наук при Правительстве Республики Мордовия. 2017. № 3 (43). С. 67-70.

2 Ульяновская область в годы Великой Отечественной войны: документы и материалы. Саратов: Приволжское кн. изд-во, 1974. С. 62.

${ }^{3}$ Пашкин А.Г., Забалухина Н.В. Симбирский - Ульяновский край в новейшей истории России. $1917-$ 1991. Люди, события, факты. Ульяновск: Корпорация технологий продвижения, 2012. С. 89.

${ }^{4}$ Ульяновская область в годы Великой Отечественной войны: документы и материалы. Саратов: Приволжское кн. изд-во, 1974. С. 120.

${ }^{5}$ Государственный архив новейшей истории Ульяновской области (далее - ГАНИ УО). Ф. 8. ОП. 2. Д. 310. Л. 65.

${ }^{6}$ ГАНИ УО. Ф. 8. ОП. 2. Д. 311. Л. 15.

${ }^{7}$ Пономаренко И.В. Деятельность промышленных предприятий малых городов среднего Поволжья в 1941-1945 гг. // Известия Самарского научного центра Российской академии наук. 2014. T. 16. № 3. C. 115-122.
${ }^{8}$ ГАНИ УО. Ф. 8. ОП. 2. Д. 313. Л. 21.

9 Там же. Д. 315. Л. 15.

${ }^{10}$ Государственный архив Ульяновской области (далее - ГАУО). Ф. Р-1548. Оп. 3. Д. 27. Л. 8.

11 Там же. Л. 9.

12 ГАУО. Ф. Р-1548. ОП. 3. Д. 29. Л. 13.

13 Там же. Д. 32. Л. 15.

14 Кондратенко Е.Ф. Промышленное строительство в годы Великой Отечественной войны 1941-1945 гг.: по материалам Среднего Поволжья: дис. ... канд. ист. наук. Пенза, 2002. С. 56.

15 ГАУО. Ф. Р-99. ОП. 2. Д. 5. Л. 4.

16 Там же. Д. 7. Л. 7.

17 Там же. Д. 11. Л. 9.

18 Кондратенко Е.Ф. Промышленное строительство в годы Великой Отечественной войны 1941-1945 гг.: по материалам Среднего Поволжья: дис. ... канд. ист. наук. Пенза, 2002. С. 58.

19 ГАУО. Ф. Р-3137. ОП. 1. Д. 35. Л. 10.

20 Пашкин А.Г., Забалухина Н.В. Симбирский Ульяновский край в новейшей истории России. 1917-1991. Люди, события, факты. Ульяновск: Корпорация технологий продвижения, 2012. С. 31.

21 ГАНИ УО. Ф. 8. ОП. 2. Д. 318. Л. 28.

22 Там же. Д. 319. Л. 9.

23 Там же. Д. 318. Л. 15.

24 Там же. Д. 320. Л. 5.

25 ГАНИ УО. Ф. 8. ОП. 3. Д. 320. Л. 15.

26 Там же. Д. 318. Л. 32.

27 Там же. Д. 319. Л. 8.

28 Там же. Д. 320. Л. 14.

29 Мухамедов Р.А., Хисамов М.И. Развитие пассажирского автотранспортного сообщения в Ульяновской области в 1956-1965 гг. // Манускрипт. Изд-во Грамота. 2020. № 5 (115) С.41-45.

30 Мухамедов Р.А., Акимова А.И. Состояние трудовой дисциплины на базовом предприятии учреждений трудовых резервов - заводе имени Володарского в 1941-1945 гг. // Вопросы национальных и федеративных отношений. Выпуск 4 (61). 2020. Том 10. С. 680-687.

${ }^{31}$ ГАУО. Ф. Р-3137. ОП. 1. Д. 41. Л. 6.

32 Там же. Д. 44. Л. 9.

33 Там же. Д. 46. Л. 11.

34 Гумбурт Н. Работать рентабельно // Ульяновская правда. 1944. 19 июля.

35 ГАУО. Ф. Р-3137. ОП. 1. Д. 47. Л. 7.

36 Там же. Д. 49. Л. 8.

37 Мосейкина А. Как я стала ткачихой // Ульяновская правда. 1944. 19 июля.

38 ГАУО. Ф. Р-3137. ОП. 1. Д. 51. Л. 7.

39 Александров Б. 700 тысяч рублей экономии // Ульяновская правда. 1944. 19 июля.

40 ГАНИ УО. Ф. 8. ОП. 3. Д. 318. Л. 34. 
41 Там же. Д. 319. Л. 10.

42 мухамедов Р.А., Хисамов М.И. Социальная защита особой группы населения в годы Великой Отечественной войны (на материалах Ульяновской области // Вопросы национальных и федеративных отношений. Выпуск 4 (61). 2020. Том 10. С. 709-716.

${ }^{43}$ ГАНИ УО. Ф. 8. ОП. 2. Д. 320. Л. 39.

${ }^{44}$ ГАУО. Ф. Р-3137. ОП. 1. Д. 41. Л. 7.
45 Там же. Д. 48. Л. 11.

46 Там же. Д. 51. Л. 16.

47 ГАНИ УО. Ф. 8. ОП. 3. Д. 319. Л. 38.

48 Лебедев В. Агитколлектив фабрики // Ульяновская правда. 1945. 21 октября.

49 ГАУО. Ф. Р-3144. ОП. 1. Д. 10. Л. 7.

50 Там же. Д. 13. Л. 6.

51 Там же. Д. 8. Л. 14.

${ }^{52}$ ГАНИ УО. Ф. 8. ОП. 3. Д. 320. Л. 51.

\title{
TEXTILE INDUSTRY OF THE ULYANOVSK REGION IN 1941-1945
}

\author{
(c) 2020 M.V. Chigrin
}

\section{Ulyanovsk State University named after I.N. Ulyanov}

The article is devoted to the development of the textile branch of the light industry of the Ulyanovsk region in 1941-1945 and written on the basis of previously unknown archive documents. The author considers the indicators of work of the textile enterprises, the course of socialist competitions, and also analyses the factors that impeded the development of production capacities.

Keywords: World War II, Ulyanovsk Region, production activities, sewing factories, products, raw materials.

DOI: $10.37313 / 2658-4816-2020-2-2-32-40$ 